\title{
The association between nutritional status and household sanitation among rural children in the Tibetan and Sichuan minority areas: a cross- sectional study
}

\section{Xian Zhu}

Chongqing Medical University https://orcid.org/0000-0003-0254-5349

Chenglu Liu

Chongqing Medical University

\section{Chang Xu}

Chongqing Medical University

Mingjing Li

Chongqing Medical University

\section{Wei Jiang}

Chongqing Medical University

\section{Xiaofeng Zhang}

Chongqing Medical University

Yajun Liu

Chongqing Medical University

Hong Xu ( $\nabla$ xuhong@cqmu.edu.cn )

Chongqing Medical University

Research article

Keywords: Malnutrition, Household sanitation, Children under 5, National minority

Posted Date: January 10th, 2020

DOI: https://doi.org/10.21203/rs.2.20580/v1

License: (c) (i) This work is licensed under a Creative Commons Attribution 4.0 International License. Read Full License 


\section{Abstract}

Background: To investigate the nutritional status and household sanitation among children under 5 in Tibetan and Sichuan minority areas and to analyse the association between nutritional status and household sanitation. Methods: A cross-sectional survey was conducted by the probability proportional to size sampling method between August and October 2016. Nutritional status was evaluated according to the standards of growth and development recommended by the World Health Organization. Bivariate and multivariate logistic regression analyses were used to analyse the association between nutritional status and household sanitation.

Results: A total of 965 children under the age of 5 and their caregivers were included. The rates of normal development, stunting, underweight, wasting, overweight and obesity of children in Sichuan and Tibet were $69.0 \%, 19.8 \%, 8.0 \%, 5.2 \%, 4.6 \%$ and $1.8 \%$, respectively. The multivariable logistic regression analyses shows that other unprotected water sources ( $A O R=3.21,95 \% \mathrm{Cl}=1.41 \sim 7.32)$, unboiled drinking water (AOR=2.05, 95\% Cl=1.41 2.97), sanitary and dry toilets ( $A O R=2.04,95 \% \mathrm{Cl}=1.12 \sim 3.71)$, unsanitary and dry toilets (AOR=2.80, 95\%Cl=1.42 5.51), usually do not washing hands at critical times (AOR=2.11, $95 \% \mathrm{Cl}=1.15 \sim 3.90)$, washing hands only with water $(\mathrm{AOR}=1.53,95 \% \mathrm{Cl}=1.03 \sim 2.26)$ and unsanitary treatment of children's faeces ( $A O R=1.56,95 \% \mathrm{Cl}=1.11 \sim 2.20)$ were the risk factors for stunting in children. Protected well water $(\mathrm{AOR}=4.28,95 \% \mathrm{Cl}=1.46 \sim 12.52)$, other unprotected water sources ( $\mathrm{AOR}=4.30$, $95 \% \mathrm{Cl}=1.36 \sim 13.61)$, unsanitary and dry toilets $(\mathrm{AOR}=4.44,95 \% \mathrm{Cl}=1.26 \sim 15.59)$, washing hands at only one critical moment $(\mathrm{AOR}=2.77,95 \% \mathrm{Cl}=1.15 \sim 6.65)$, washing hands only with water $(\mathrm{AOR}=2.22$, $95 \% \mathrm{Cl}=1.20 \sim 4.09$ ) and unsanitary treatment of children's faeces ( $\mathrm{AOR}=2.01,95 \% \mathrm{Cl}=1.23 \sim 3.28$ ) were risk factors for underweight in children.

Conclusion: The malnutrition of children under 5 years of age in the rural areas home to ethnic minorities in Sichuan and Tibet is serious, and the problem of stunting is particularly prominent. The children's household sanitation status is poor, and the family's economic income has an impact on household sanitation; thus, household sanitation has an impact on both the height and the weight of the child. The relevant departments should increase the family's economic income while conducting household sanitation interventions, thereby reducing the incidence and mortality due to malnutrition.

\section{Background}

The World Health Organization (WHO) estimated in 2018 that approximately 52 million children under the age of 5 are wasting, 17 million are severely wasting, 155 million are stunted, 41 million are overweight/obese, and approximately $45 \%$ of deaths among children under 5 are related to malnutrition [1]. Children aged $0 \sim 5$ years old are the age group most likely to suffer malnutrition, and nutritional status in the early stage of life is directly related to subsequent growth and development, learning, cognitive ability and even labour productivity in adulthood ${ }^{[2-4]}$. In 2012, the World Health Assembly planned to reduce global under-five malnutrition to less than 100 million children by 2025 and to end all forms of malnutrition by $2030^{[5-6]}$. 
The incidence of child malnutrition has decreased greatly since China's economic reform. In 1990, the rate of stunting among children under 5 years of age in China was $31.3 \%$, and the rate of underweight was $7.4 \%$. In 2010 , these figures decreased to $9.4 \%$ and $3.4 \%$, respectively ${ }^{[7]}$. However, the differences between urban and rural areas and regions cannot be ignored; the rates are obviously higher in rural areas than in urban areas, and the rates are obviously higher in poor areas than in economically developed areas ${ }^{[8-11]}$. A previous study showed that the rate of stunting among children under 5 years of age was $15.9 \%$, the underweight rate was $7.8 \%$, and the wasting rate was $3.7 \%$ in poor areas of China ${ }^{[12]}$. In 2017 , the National Nutrition Plan issued by the State Council of China (2017-2030) explicitly stated that the rate of stunting among children under 5 should be less than 7\% in 2020 and below $5 \%$ in 2030, indicating the main development goal of child nutrition ${ }^{[13]}$.

Tibet and Yi nationality areas of Sichuan are located in western China, which is a relatively backward economic area. In addition, the Tibetan and Yi ethnic minorities are the two of the most representative ethnic minorities in China, with the most complete national customs and habits and the most prominent national characteristics. A survey conducted in 2011 showed that the rates of stunting, underweight and wasting among children in the minority areas of Sichuan and Tibet were $30.5 \%, 16.5 \%$ and $1.6 \%$, respectively ${ }^{[14]}$, which are much higher than those of children in other parts of China; therefore, these children should receive increasing attention from relevant Chinese and international bodies.

Household sanitation refers to all family-related sanitation, including household sanitation facilities, such as toilets, drinking water sanitation and the hygiene behaviour of caregivers and children. There are many factors that affect the malnutrition of children, mainly including the family financial situation, the child's age, feeding habits, hygiene behaviour and the child's state of health. Studies have shown that there is a clear correlation between childhood acute malnutrition and family environmental hygiene ${ }^{[15-17]}$. However, there are few studies on the effect of household sanitation on chronic malnutrition in children in China. Therefore, the purpose of this study is to analyse the association between household sanitation and the nutritional status of children and to provide a scientific basis for improving the nutritional status of rural children in poor minority areas and promoting the healthy growth of children.

\section{Methods}

\section{Study population}

A cross-sectional survey was conducted from August to October 2016, and the main investigated areas were Ganluo County and Yuexi County in Liangshan Yi Autonomous Prefecture of Sichuan and Saga County and Aung Ren County in Xigaze region of Tibet. The study population included children under 5 years of age and their caregivers. The inclusion criteria were as follows: 1 . The children's age range: the children were born after the date of the 2011 survey; 2 . Long-term local residence: the local residence time was $2 / 3$ greater than the child's age. The exclusion criterion was that the children were not at home at the time of the investigation. 


\section{Sampling Methods}

The probability proportional to size (PPS) sampling was used to select sample villages. The main steps were as follows: step 1: 15 administrative villages were randomly selected in each county according to the PPS sampling method; step 2: 2 natural villages in each administrative village were randomly selected by PPS sampling; step 3: In Sichuan, after the natural village was determined, 8 caregivers were randomly selected from each natural village according to the family roster containing children under 5 years of age. In Tibet, administrative villages could not be divided into natural villages, and 5 caregivers were randomly selected from each administrative village according to the family roster containing children under 5 years of age. If a sample village failed to meet the proposed sample size, another sample village was randomly selected in the same layer until the intended sample size was achieved. The number of people surveyed in each county of Sichuan needed to reach 240, and the number of people surveyed in each county of Tibet needed to reach 70. At least 620 caregivers of children under the age of five were investigated in Sichuan and Tibet. (8 or 5 households in each natural village were chosen for the survey because the Tibetan and Sichuan Yi areas are sparsely populated.)

\section{Survey Tool}

The survey was conducted using the questionnaire designed by the Maternal and Child Health Project expert group. The main contents included the basic characteristics of the children and their caregivers, the feeding situation of the children, the situation of household sanitation and the physical examination of the children (height and weight), etc.

\section{Data Collection and Quality Control}

All investigators were uniformly trained, with an investigation team of 4 to 5 qualified investigators led by local village doctors. Using one-on-one question and answer, the investigators filled out questionnaires on the panel computer on the spot. The questionnaires were checked one by one by the investigators and team leaders on the night of the survey and uploaded to the database. Finally, the data verification was carried out by the evaluation team of Peking University. The physical examination of each child was carried out by two investigators using standardized equipment in accordance with the international standard method of measurement ${ }^{[18]}$. The body length in bed was measured for children less than or equal to 2 years old, and the standing height was measured for children older than 2 years old. Each child's length/height and weight were measured twice to take the mean value. A third measurement was required if the error of the two measures was greater than $0.05 \mathrm{~kg}$ for weight and more than $0.1 \mathrm{~cm}$ for length/height.

\section{Definitions}

1. Evaluation indicators: child growth and development standards published by the WHO in $2006^{[18]}$. Length/height-for-age (HAZ) < median - 2 standard deviation (M-2SD) was considered stunting; weight-for-age (WAZ) < M-2SD was considered underweight; weight-for-height (WHZ) < M-2SD was 
considered wasting, $M+2 S D \sim M+3 S D$ was considered overweight, >M+3SD was considered obese; children without stunting, underweight, wasting, overweight and obesity were defined as normally developing.

2. The children were divided into 5 groups according to their age in months: 0 11 months, 12 23 months, 24 35 months, 36 47 months, and 48 59 months.

3. Washing hands at critical moments: a total of 8 critical moments are listed, namely, after the completion of agricultural work, before cooking, before dining, before feeding the baby, after defecation, after handling the child's faeces, other and usually do not wash hands. The analysis was grouped by number, and the four groups include the option usually do not wash hands, 1, 2, 3 and above.

\section{Statistical Analysis}

The data were downloaded directly from the database into the statistical software and analysed by IBMSPSS 21.0 software. The Shapiro-Wilk test and Q-Q plots were used to check for normality of the continuous variables. The statistical analysis methods used mainly include the following: the basic characteristics of children and caregivers were described by the constituent ratio, the difference was compared adopting the chi-square test, and the influencing factors were analysed by bivariate and multivariate logistic regression analysis. All statistical analyses were two-tailed, and an a of 0.05 denoted statistical significance.

\section{Results}

\section{Basic Characteristics of Children and Their Caregivers}

A total of 965 children under 5 and their caregivers were included in this study. Of these, $51.7 \%$ were boys; those aged $0 \sim, 12 \sim, 24 \sim, 36 \sim$ and $48 \sim 59$ months accounted for $33.5 \%, 28.2 \%, 20.7 \%, 10.5 \%$ and $7.2 \%$, respectively. By location, those in Sichuan accounted for $84.5 \%$, and those in Tibet accounted for $15.5 \%$; Yi represented the largest proportion by nationality, with 71.7\%. A total of 721 (74.7\%) mothers were surveyed, of whom $85.4 \%$ were illiterate/had primary school education; there were 438 (45.4\%) missing values for household per capita net income. Incomes of $0 \sim, 2000 \sim$ and $\geq 5000$ yuan were reported by $36.8 \%, 40.0 \%$ and $23.1 \%$ of the families, respectively. (Table 1 ) 
Table 1

Basic characteristics of children and their caregivers $(n=965)$

\begin{tabular}{|c|c|c|c|}
\hline Variables & & $\mathrm{n}$ & $\%$ \\
\hline \multirow[t]{2}{*}{ Gender } & boy & 499 & 51.7 \\
\hline & girl & 466 & 48.3 \\
\hline \multirow[t]{5}{*}{ Age(month) } & $0 \sim$ & 323 & 33.5 \\
\hline & $12 \sim$ & 272 & 28.2 \\
\hline & $24 \sim$ & 200 & 20.7 \\
\hline & $36 \sim$ & 101 & 10.5 \\
\hline & $48 \sim 59$ & 69 & 7.2 \\
\hline \multirow[t]{2}{*}{ Area } & Sichuan & 815 & 84.5 \\
\hline & Tibet & 150 & 15.5 \\
\hline \multirow[t]{3}{*}{ Nationality } & Han & 117 & 12.1 \\
\hline & $Y i$ & 692 & 71.7 \\
\hline & Tibetan & 156 & 16.2 \\
\hline \multirow[t]{2}{*}{ Caregivers } & mother & 721 & 74.7 \\
\hline & others & 244 & 25.3 \\
\hline Mother's educational level & illiterate / primary school & 616 & 85.4 \\
\hline \multirow[t]{2}{*}{$(n=721)$} & junior middle school & 88 & 12.2 \\
\hline & senior high school and above & 17 & 2.4 \\
\hline Family income (yuan) & $0 \sim$ & 194 & 36.8 \\
\hline \multirow[t]{2}{*}{$(n=527)$} & $2000 \sim$ & 211 & 40.0 \\
\hline & $\geq 5000$ & 122 & 23.1 \\
\hline
\end{tabular}

Nutritional Status of Children

The rates of stunting, underweight, wasting, overweight, obesity and normal development among the children were $19.8 \%, 8.0 \%, 5.2 \%, 4.6 \%, 1.8 \%$ and $69.0 \%$, respectively. There were significant differences in the normal development rate, stunting rate, overweight rate and obesity rate among children of different ages. There were significant differences in the normal development rate, stunting rate and overweight rate among boys of different ages. The differences in the normal developmental rate, stunting rate and obesity rate among girls of different ages were statistically significant. With increasing age, the rate of 
normally developing children decreased, and the minimum normal development rate among boys between 48 and 59 months was $55.0 \%$. With the increase in the age of the child, the rate of stunting increased, and the rate of stunting of boys of $48 \sim 59$ months was up to $37.5 \%$. (Table 2) 
Table 2

Assessment of the status of children's malnutrition ( $\mathrm{n}=965)(\%)$

\begin{tabular}{|c|c|c|c|c|c|c|c|}
\hline Gender & $\begin{array}{l}\text { Age } \\
\text { (month) }\end{array}$ & Stunting & Underweight & Wasting & Overweight & Obesity & $\begin{array}{l}\text { Normal } \\
\text { development }\end{array}$ \\
\hline \multirow[t]{6}{*}{ Boys } & $0 \sim$ & 6.2 & 6.8 & 8.0 & 8.0 & 2.5 & 74.1 \\
\hline & $12 \sim$ & 18.8 & 6.9 & 3.5 & 2.1 & 0 & 73.6 \\
\hline & $24 \sim$ & 30.4 & 8.8 & 4.9 & 2.9 & 2.0 & 62.7 \\
\hline & $36 \sim$ & 29.4 & 3.9 & 2.0 & 2.0 & 2.0 & 64.7 \\
\hline & $48 \sim 59$ & 37.5 & 5.0 & 5.0 & 10.0 & 0 & 55.0 \\
\hline & total & 19.6 & 6.8 & 5.2 & 4.8 & 1.4 & 69.1 \\
\hline$x^{2}$ & & $33.596^{\mathrm{a}}$ & 1.532 & 4.592 & 10.031 & 6.593 & $7.819^{a}$ \\
\hline $\mathrm{P}$ & & $<0.001$ & 0.821 & 0.332 & 0.040 & 0.159 & 0.005 \\
\hline \multirow[t]{6}{*}{ Girls } & $0 \sim$ & 5.6 & 6.8 & 5.6 & 6.2 & 4.3 & 75.2 \\
\hline & $12 \sim$ & 21.1 & 10.9 & 4.7 & 1.6 & 0 & 72.7 \\
\hline & $24 \sim$ & 33.7 & 9.2 & 5.1 & 4.1 & 3.1 & 58.2 \\
\hline & $36 \sim$ & 32.0 & 8.0 & 4.0 & 6.0 & 0 & 62.0 \\
\hline & $48 \sim 59$ & 27.6 & 17.2 & 6.9 & 3.4 & 0 & 65.5 \\
\hline & total & 20.0 & 9.2 & 5.2 & 4.3 & 2.1 & 68.9 \\
\hline$x^{2}$ & & $27.759^{a}$ & 3.863 & 0.437 & 4.181 & 12.202 & $6.269^{a}$ \\
\hline$P$ & & $<0.001$ & 0.425 & 0.979 & 0.382 & 0.016 & 0.012 \\
\hline \multirow[t]{6}{*}{ Total } & $0 \sim$ & 5.9 & 6.8 & 6.8 & 7.1 & 3.4 & 74.6 \\
\hline & $12 \sim$ & 19.9 & 8.8 & 4.0 & 1.8 & 0 & 73.2 \\
\hline & $24 \sim$ & 32.0 & 9.0 & 5.0 & 3.5 & 2.5 & 60.5 \\
\hline & $36 \sim$ & 30.7 & 5.9 & 3.0 & 4.0 & 1.0 & 63.4 \\
\hline & $48 \sim 59$ & 33.3 & 10.1 & 5.8 & 7.2 & 0 & 59.4 \\
\hline & total & 19.8 & 8.0 & 5.2 & 4.6 & 1.8 & 69.0 \\
\hline$x^{2}$ & & $61.302^{a}$ & 2.161 & 3.534 & 11.242 & 17.063 & $14.069^{a}$ \\
\hline$P$ & & $<0.001$ & 0.706 & 0.473 & 0.024 & 0.002 & $<0.001$ \\
\hline
\end{tabular}


Among these 965 households, the source of water was purified tap water (16.0\%), water was boiled before drinking $(42.8 \%)$, the toilet was flushed $(13.0 \%)$, hands were washed at three or more critical moments $(16.5 \%)$, hands were washed with soap $(36.4 \%)$ and the child's faeces were treated hygienically (59.4\%). The results showed that there were significant differences in drinking water source, whether water was boiled before drinking, toilet type, hand washing at critical moments, washing hand mode and treatment of children's faeces among families with different incomes. (Table 3 ) 
Table 3

Comparison of the household sanitation of children in different family income $(n=527)$

\begin{tabular}{|c|c|c|c|c|c|c|}
\hline \multirow[t]{2}{*}{ Varaibles } & & \multicolumn{3}{|c|}{ Family income (\%) } & \multirow[t]{2}{*}{$\chi^{2}$} & \multirow[t]{2}{*}{$\mathrm{P}$} \\
\hline & & $0 \sim$ & $2000 \sim$ & $\geq 5000$ & & \\
\hline \multirow[t]{4}{*}{ Drinking water source } & purified tap water & $33(17.0)$ & $28(13.3)$ & $44(36.1)$ & 28.469 & $\begin{array}{l}< \\
0.001\end{array}$ \\
\hline & $\begin{array}{l}\text { protected well } \\
\text { water }\end{array}$ & 21(10.8) & $31(14.7)$ & 13(10.7) & & \\
\hline & $\begin{array}{l}\text { unprotected well } \\
\text { water }\end{array}$ & $125(64.4)$ & $132(62.6)$ & $58(47.5)$ & & \\
\hline & others & $15(7.7)$ & $20(9.5)$ & $7(5.7)$ & & \\
\hline \multirow[t]{2}{*}{$\begin{array}{l}\text { Boiling before } \\
\text { drinking }\end{array}$} & boiled & $68(35.1)$ & 111(52.6) & $76(62.3)$ & 24.768 & $\begin{array}{l}< \\
0.001\end{array}$ \\
\hline & unboiled & $126(64.9)$ & $100(47.4)$ & $46(37.7)$ & & \\
\hline \multirow[t]{4}{*}{ Toilet type } & $\begin{array}{l}\text { flush sanitary } \\
\text { toilet }\end{array}$ & $18(9.3)$ & $22(10.4)$ & $31(25.4)$ & 39.831 & $\begin{array}{l}< \\
0.001\end{array}$ \\
\hline & $\begin{array}{l}\text { flush unsanitary } \\
\text { toilet }\end{array}$ & $1(0.5)$ & $17(8.1)$ & $6(4.9)$ & & \\
\hline & $\begin{array}{l}\text { sanitary and dry } \\
\text { toilet }\end{array}$ & $123(63.4)$ & 137(64.9) & $70(57.4)$ & & \\
\hline & $\begin{array}{l}\text { unsanitary and dry } \\
\text { toilet }\end{array}$ & $52(26.8)$ & $35(16.6)$ & $15(12.3)$ & & \\
\hline \multirow[t]{4}{*}{$\begin{array}{l}\text { Washing hands at } \\
\text { critical moments }\end{array}$} & $\begin{array}{l}\text { usually don not } \\
\text { wash hands }\end{array}$ & $27(13.9)$ & $22(10.4)$ & $6(4.9)$ & 17.377 & 0.008 \\
\hline & one & $89(45.9)$ & $81(38.4)$ & 48(39.3) & & \\
\hline & two & $54(27.8)$ & $65(30.8)$ & $34(27.9)$ & & \\
\hline & three and above & $24(12.4)$ & $43(20.4)$ & $34(27.9)$ & & \\
\hline \multirow[t]{2}{*}{ Washing hand mode } & soap & $49(25.3)$ & 74(35.1) & $60(49.2)$ & 18.929 & $\begin{array}{l}< \\
0.001\end{array}$ \\
\hline & only water & $145(74.7)$ & $137(64.9)$ & $62(50.8)$ & & \\
\hline \multirow{2}{*}{$\begin{array}{l}\text { Child's faeces } \\
\text { treatment }\end{array}$} & sanitary & $99(51.0)$ & $128(60.7)$ & $85(69.7)$ & 11.087 & 0.004 \\
\hline & unsanitary & $95(49.0)$ & $83(39.3)$ & $37(30.3)$ & & \\
\hline
\end{tabular}

The Association between Nutritional Status and Household Sanitation 
After adjusting for factors such as age, gender and region, other unprotected water sources (AOR $=3.21$, $95 \% \mathrm{Cl}=1.41 \sim 7.32)$, unboiled drinking water $(\mathrm{AOR}=2.05,95 \% \mathrm{Cl}=1.41 \sim 2.97)$, sanitary and dry toilets $(\mathrm{AOR}=2.04,95 \% \mathrm{Cl}=1.12 \sim 3.71)$, unsanitary and dry toilets $(\mathrm{AOR}=2.80,95 \% \mathrm{Cl}=1.42 \sim 5.51)$, usually do not washing hands at critical moments $(A O R=2.11,95 \% \mathrm{Cl}=1.15 \sim 3.90)$, washing hands only with water $(\mathrm{AOR}=1.53,95 \% \mathrm{Cl}=1.03 \sim 2.26)$, and unsanitary treatment of children's faeces $(\mathrm{AOR}=1.56,95 \% \mathrm{Cl}=$ $1.11 \sim 2.20$ ) were risk factors for stunting in children.

After adjusting for factors such as age, gender and region, protected well water (AOR $=4.28,95 \% \mathrm{Cl}=1.46$ $\sim 12.52)$, other unprotected water sources $(A O R=4.30,95 \% \mathrm{Cl}=1.36 \sim 13.61)$, unsanitary and dry toilets $(\mathrm{AOR}=4.44,95 \% \mathrm{Cl}=1.26 \sim 15.59)$, washing hands at only one critical moment $(\mathrm{AOR}=2.77,95 \% \mathrm{Cl}=1.15$ $\sim 6.65)$, washing hands only with water $(\mathrm{AOR}=2.22,95 \% \mathrm{Cl}=1.20 \sim 4.09)$ and unsanitary treatment of children's faeces $(\mathrm{AOR}=2.01,95 \% \mathrm{Cl}=1.23 \sim 3.28)$ were risk factors for underweight in children. (Table 4) 
Table 4

The effect of the different household sanitation on the nutritional status of children

\begin{tabular}{|c|c|c|c|c|c|c|}
\hline Varaibles & & $\begin{array}{l}\text { Morbidity } \\
\text { rate(\%) }\end{array}$ & $\operatorname{coR}(95 \% \mathrm{Cl})$ & $\mathbf{P}$ & AOR(95\%Cl) & $\mathbf{P}$ \\
\hline \multicolumn{7}{|l|}{ Stunting } \\
\hline \multirow[t]{4}{*}{$\begin{array}{l}\text { Drinking water } \\
\text { source }\end{array}$} & $\begin{array}{l}\text { purified tap } \\
\text { water }\end{array}$ & 13.6 & 1 & & 1 & \\
\hline & $\begin{array}{l}\text { protected well } \\
\text { water }\end{array}$ & 25.6 & $\begin{array}{l}2.18(1.12 \sim \\
4.25)\end{array}$ & 0.022 & $\begin{array}{l}1.98(0.92 \sim \\
4.24)\end{array}$ & 0.081 \\
\hline & $\begin{array}{l}\text { unprotected } \\
\text { well water }\end{array}$ & 19.4 & $\begin{array}{l}1.52(0.92 \sim \\
2.51)\end{array}$ & 0.100 & $\begin{array}{l}1.38(0.82 \sim \\
2.31)\end{array}$ & 0.223 \\
\hline & others & 31.3 & $\begin{array}{l}2.88(1.43 \sim \\
5.80)\end{array}$ & 0.003 & $\begin{array}{l}3.21(1.41 \sim \\
7.32)\end{array}$ & 0.005 \\
\hline \multirow{2}{*}{$\begin{array}{l}\text { Boiling before } \\
\text { drinking }\end{array}$} & boiled & 15.0 & 1 & & 1 & \\
\hline & unboiled & 23.4 & $\begin{array}{l}1.73(1.24 \sim \\
2.41)\end{array}$ & 0.001 & $\begin{array}{l}2.05(1.41 \sim \\
2.97)\end{array}$ & $\begin{array}{l}< \\
0.001\end{array}$ \\
\hline \multirow[t]{4}{*}{ Toilet type } & $\begin{array}{l}\text { flush sanitary } \\
\text { toilet }\end{array}$ & 12.0 & 1 & & 1 & \\
\hline & $\begin{array}{l}\text { flush } \\
\text { unsanitary } \\
\text { toilet }\end{array}$ & 17.3 & $\begin{array}{l}1.54(0.63 \sim \\
3.77)\end{array}$ & 0.350 & $\begin{array}{l}1.91(0.75 \sim \\
4.85)\end{array}$ & 0.173 \\
\hline & $\begin{array}{l}\text { sanitary and } \\
\text { dry toilet }\end{array}$ & 19.8 & $\begin{array}{l}1.82(1.02 \sim \\
3.22)\end{array}$ & 0.042 & $\begin{array}{l}2.04(1.12 \sim \\
3.71)\end{array}$ & 0.020 \\
\hline & $\begin{array}{l}\text { unsanitary and } \\
\text { dry toilet }\end{array}$ & 26.2 & $\begin{array}{l}2.60(1.37 \sim \\
4.93)\end{array}$ & 0.003 & $\begin{array}{l}2.80(1.42 \sim \\
5.51)\end{array}$ & 0.003 \\
\hline \multirow[t]{4}{*}{$\begin{array}{l}\text { Washing hands at } \\
\text { critical moments }\end{array}$} & $\begin{array}{l}\text { usually don not } \\
\text { wash hands }\end{array}$ & 15.1 & 1 & & 1 & \\
\hline & one & 28.3 & $\begin{array}{l}2.22(1.24 \sim \\
4.01)\end{array}$ & 0.008 & $\begin{array}{l}2.11(1.15 \sim \\
3.90)\end{array}$ & 0.017 \\
\hline & two & 20.9 & $\begin{array}{l}1.49(0.91 \sim \\
2.43)\end{array}$ & 0.116 & $\begin{array}{l}1.52(0.91 \sim \\
2.53)\end{array}$ & 0.111 \\
\hline & three and above & 16.9 & $\begin{array}{l}1.14(0.66 \sim \\
1.97)\end{array}$ & 0.635 & $\begin{array}{l}1.14(0.65 \sim \\
2.00)\end{array}$ & 0.660 \\
\hline \multirow{2}{*}{$\begin{array}{l}\text { Washing hand } \\
\text { mode }\end{array}$} & soap & 15.1 & 1 & & 1 & \\
\hline & only water & 21.0 & $\begin{array}{l}1.50(1.04 \sim \\
2.15)\end{array}$ & 0.030 & $\begin{array}{l}1.53(1.03 \sim \\
2.26)\end{array}$ & 0.034 \\
\hline Child's faeces & sanitary & 18.3 & 1 & & 1 & \\
\hline
\end{tabular}




\begin{tabular}{|c|c|c|c|c|c|c|}
\hline \multirow[t]{2}{*}{ Varaibles } & & $\begin{array}{l}\text { Morbidity } \\
\text { rate(\%) }\end{array}$ & $\operatorname{COR}(95 \% \mathrm{Cl})$ & $\mathbf{P}$ & $\operatorname{AOR}(95 \% \mathrm{Cl})$ & $\mathbf{P}$ \\
\hline & unsanitary & 21.9 & $\begin{array}{l}1.25(0.91 \sim \\
1.72)\end{array}$ & 0.167 & $\begin{array}{l}1.56(1.11 \sim \\
2.20)\end{array}$ & 0.011 \\
\hline \multicolumn{7}{|l|}{ Underweight } \\
\hline \multirow[t]{4}{*}{$\begin{array}{l}\text { Drinking water } \\
\text { source }\end{array}$} & $\begin{array}{l}\text { purified tap } \\
\text { water }\end{array}$ & 3.9 & 1 & & 1 & \\
\hline & $\begin{array}{l}\text { protected well } \\
\text { water }\end{array}$ & 17.4 & $\begin{array}{l}5.21(1.94 \sim \\
14.00)\end{array}$ & 0.001 & $\begin{array}{l}4.28(1.46 \sim \\
12.52)\end{array}$ & 0.008 \\
\hline & $\begin{array}{l}\text { unprotected } \\
\text { well water }\end{array}$ & 6.8 & $\begin{array}{l}1.80(0.76 \sim \\
4.30)\end{array}$ & 0.185 & $\begin{array}{l}1.87(0.77 \sim \\
4.52)\end{array}$ & 0.166 \\
\hline & others & 17.2 & $\begin{array}{l}5.12(1.80 \sim \\
14.53)\end{array}$ & 0.002 & $\begin{array}{l}4.30(1.36 \sim \\
13.61)\end{array}$ & 0.013 \\
\hline \multirow{2}{*}{$\begin{array}{l}\text { Boiling before } \\
\text { drinking }\end{array}$} & boiled & 8.5 & 1 & & 1 & \\
\hline & unboiled & 7.6 & $\begin{array}{l}0.89(0.56 \sim \\
1.42)\end{array}$ & 0.623 & $\begin{array}{l}1.20(0.72 \sim \\
2.01)\end{array}$ & 0.491 \\
\hline \multirow[t]{4}{*}{ Toilet type } & $\begin{array}{l}\text { flush sanitary } \\
\text { toilet }\end{array}$ & 2.4 & 1 & & 1 & \\
\hline & $\begin{array}{l}\text { flush } \\
\text { unsanitary } \\
\text { toilet }\end{array}$ & 5.8 & $\begin{array}{l}2.49(0.47 \sim \\
12.76)\end{array}$ & 0.274 & $\begin{array}{l}2.48(0.48 \sim \\
12.77)\end{array}$ & 0.277 \\
\hline & $\begin{array}{l}\text { sanitary and } \\
\text { dry toilet }\end{array}$ & 8.1 & $\begin{array}{l}3.57(1.10 \sim \\
11.63)\end{array}$ & 0.035 & $\begin{array}{l}3.03(0.92 \sim \\
9.98)\end{array}$ & 0.068 \\
\hline & $\begin{array}{l}\text { unsanitary and } \\
\text { dry toilet }\end{array}$ & 12.5 & $\begin{array}{l}5.81(1.69 \sim \\
19.94)\end{array}$ & 0.005 & $\begin{array}{l}4.44(1.26 \sim \\
15.59)\end{array}$ & 0.020 \\
\hline \multirow[t]{4}{*}{$\begin{array}{l}\text { Washing hands at } \\
\text { critical moments }\end{array}$} & $\begin{array}{l}\text { usually don not } \\
\text { wash hands }\end{array}$ & 3.8 & 1 & & 1 & \\
\hline & one & 9.2 & $\begin{array}{l}2.57(0.92 \sim \\
7.17)\end{array}$ & 0.071 & $\begin{array}{l}2.18(0.77 \sim \\
6.13)\end{array}$ & 0.141 \\
\hline & two & 10.2 & $\begin{array}{l}2.90(1.21 \sim \\
6.94)\end{array}$ & 0.017 & $\begin{array}{l}2.77(1.15 \sim \\
6.65)\end{array}$ & 0.023 \\
\hline & three and above & 6.3 & $\begin{array}{l}1.71(0.65 \sim \\
4.46)\end{array}$ & 0.275 & $\begin{array}{l}1.56(0.59 \sim \\
4.09)\end{array}$ & 0.370 \\
\hline \multirow{2}{*}{$\begin{array}{l}\text { Washing hand } \\
\text { mode }\end{array}$} & soap & 4.3 & 1 & & 1 & \\
\hline & only water & 10.3 & $\begin{array}{l}2.57(1.42 \sim \\
4.66)\end{array}$ & 0.002 & $\begin{array}{l}2.22(1.20 \sim \\
4.09)\end{array}$ & 0.011 \\
\hline $\begin{array}{l}\text { Child's faeces } \\
\text { treatment }\end{array}$ & sanitary & 5.8 & 1 & & 1 & \\
\hline
\end{tabular}




\begin{tabular}{|llllll|}
\hline Varaibles & $\begin{array}{l}\text { Morbidity } \\
\text { rate(\%) }\end{array}$ & COR(95\%Cl) & $\mathbf{P}$ & AOR(95\%Cl) & $\mathbf{P}$ \\
\hline unsanitary & 11.2 & $\begin{array}{l}2.07(1.29 \sim \\
3.31)\end{array}$ & 0.002 & $\begin{array}{l}2.01(1.23 \sim \\
3.28)\end{array}$ & 0.005 \\
\hline
\end{tabular}

\section{Discussion}

Malnutrition is still the main public health problem affecting children in poor rural areas in China. The results showed that the rates of normal development, stunting, underweight, wasting, overweight and obesity of children under 5 years old in Sichuan and Tibet were $69.0 \%, 19.8 \%, 8.0 \%, 5.2 \%, 4.6 \%$ and $1.8 \%$, respectively. The rates of stunting, underweight and wasting were higher than those according to the 2009 China Food and Nutrition Monitoring system (CFNSS) ${ }^{[19]}$ and $\mathrm{Yu}{ }^{[12]}$. It is also higher than the survey results in other ordinary rural areas, poor areas and ethnic minority areas ${ }^{[20-25]}$. The malnutrition of children in the Tibetan and Sichuan minority areas is serious, which is quite different from that in other regions. Regional differences should be reduced by improving the regional economy, lifestyle and behavioural habits to reduce the incidence of malnutrition among children.

The rate of stunting in this survey was $19.8 \%$, which was lower than the rate of $30.5 \%$ found in $2011^{\text {[26] }}$ but still much higher than the target rate of $7 \%$ in $2025^{[13]}$. The change may be a result of the common effects of socioeconomic changes, child-feeding habits and environmental hygiene changes. The rate of stunting increased with age, and the rate of stunting in the group of $48 \sim 59$-month-old boys was 37.5\%, which is consistent with the findings of previous studies ${ }^{[27-30]}$. One possible explanation is that the children were malnourished for a long time, and the higher stunting rate accompanied increasing age.

The proportion of children who die of malnutrition remains high in low-income and middle-income countries; however, overweight and obesity rates are also on the rise ${ }^{[1]}$. Stunting and overweight/obesity often coexist in economically underdeveloped areas. According to one study, in 2006, the stunting rate of children in poor areas of central and western China was $57.6 \%$, while the rate of overweight among children was as high as $16.8 \%{ }^{[8]}$. Although the survey showed that the rate of overweight and obesity was slightly lower than that in other areas, it is worth noting.

A large number of studies have shown that the higher the family's economic level is, the lower the rate of child malnutrition ${ }^{[31-36]}$. A study conducted in Vietnam has shown that the impact of socioeconomic inequality on child malnutrition increases over time and that socioeconomic status is the first cause of inequality in stunting and the second cause of inequality in underweight ${ }^{[37]}$. The study found that the sanitation situation of the family in Sichuan and Tibet was poor, and the household sanitation of the families with different economic conditions was obviously different. The household environmental sanitation may have been affected by the economic situation of the family. Therefore, in multivariate statistical analysis, there is a collinearity problem between the two, and only one of them should be included in multivariate statistical analysis. 
Our study showed that household sanitation had an important impact on the children's height and weight after adjusting for confounding factors. Thus, household sanitation may be a direct factor of the nutrition of children. Similar studies have shown that household sanitation facilities, water sources and household hygiene behaviours are major contributors to child malnutrition ${ }^{[38-40]}$. Poor sanitation is likely to have an impact on the nutritional status of children by increasing the risk that the children catch an infectious disease ${ }^{[41-44]}$. Therefore, intervention in household sanitation may reduce the malnutrition among children.

When we investigated some special areas and people groups, details about the economic situation were often difficult to obtain directly for a variety of reasons. For example, in our survey, 438 (45.4\%) people were reluctant to disclose their family income. However, household environmental sanitation conditions can be easily obtained by observation, inquiry, etc. Therefore, when conducting similar research, we can replace the less accessible variables with variables that are more easily available for investigation and analysis to improve the feasibility of the survey and the effectiveness of the data. For example, in this study, we can infer the family economic situation through investigation of the family's environmental hygiene.

This study is a cross-sectional study, which cannot be used to draw causality conclusions. Further verification research should be carried out to clarify the impact of family hygiene conditions on the nutritional status of children.

\section{Conclusions}

The malnutrition of children in the Tibetan and Sichuan minority areas is serious. Stunting, underweight and wasting among children are obvious, especially the phenomenon of stunting, which is the most serious. The household sanitation status of the children is poor, household sanitation status differs greatly according to economic income, and household sanitation can be affected by the family's economic level. The relevant departments should increase family income while conducting household sanitation interventions, thereby improving household sanitation, reducing the morbidity and mortality resulting from malnutrition, and promoting the healthy growth of children.

\section{List Of Abbreviations}

PPS: Probability Proportional to Size; WHO: World Health Organization; HAZ: length/height-for-age; WAZ: weight-for-age; WHZ: weight-for-height; $\mathrm{M} \pm S D$ : median \pm standard deviation; CFNSS: China Food and Nutrition Monitoring system; UNICEF: The United Nations Children's Fund

\section{Declarations}

Ethics approval and consent to participate All procedures involving research study participants were approved by the Ethics Committee on Biomedical Research, Department of Medicine, Peking University. 
Written informed consent was obtained from the caregivers of all the children involved in the study.

Consent for publication Not applicable.

Availability of data and materials The datasets used and/or analysed during the current study are available from the corresponding author on reasonable request.

Competing interests The authors declare that they have no competing interests.

Funding China Health and Family Planning Commission and the United Nations Children's Fund (UNICEF) "Integrated Project for the Healthy Development of Mother and Child" from 2016 to 2020. The study is funded by UNICEF. The funder was involved in study design and preparation of the investigation.

Authors' contributions $\mathrm{HX}$ designed and performed the study. XZ analyzed the data and results interpretation and wrote the paper. CLL and CX and MJL analyzed the data and paper modification. WJ, XFZ and YJL participated in data collection and quality control. All authors read and approved the final manuscript.

Acknowledgements The authors thank all the caregivers of the children for participating in the study; all the investigators involved in the project investigation, including Hong Xu, Xiaofeng Zhang, Yajun Liu, Wei Jiang, Dongtao Yin, Wei Xu, Zhen Qin, Qiang He, Jing Feng, Dan Peng, Zhongshuang Zhang, Xinxin Pu, et al, as well as the administrative units of Sichuan and Tibet and the Department of Health and local clinics for their collaboration and support.

\section{References}

[1]World Health Organization. Malnutrition. https://www.who.int/en/news-room/factsheets/detail/malnutrition. Accessed 9 November 2019.

[2]Chao F, Zhang SF, Fu PY, Zhang D. Analysis of growth, development and anemia of children under 5 years of age in rural areas of Henan Province. China Health Statistics. 2013;30,585-586.

[3]Guerrant RL, Oria RB, Moore SR, Oria MO, Lima AA. Malnutrition as an enteric infectious disease with long-term effects on child development. Nutr Rev. 2008;66:487-505.

[4]Lelijveld N, Seal A, Wells JC, Kirkby J, Opondo C, Chimwezi E, et al. Chronic disease outcomes after severe acute malnutrition in Malawian children (ChroSAM): a cohort study. Lancet Glob Health. 2016;4:e654-62.

[5]World Health Organization. Comprehensive implementation plan on maternal, infant and young child nutrition. 65th World Health Assembly. Geneva, WHO, 2012.

[6]Sustainable Development Goals.

https://sustainabledevelopment.un.org/topics/sustainabledevelopmentgoals. Accessed 9 November 
2019.

[7]Zhang Y. Study on nutritional status and influencing factors of 5-year-old children in Huangpi District of Wuhan City, Master, Huazhong University of Science and Technology. Wuhan. 2017.

[8]Zong X, Li H. Physical growth of children and adolescents in China over the past 35 years. Bull World Health Organ. 2014,92,555-564.

[9] He ZQ, Sun Y, Yang HP, Luo Y, Yan M, Chen L. Epidemiological survey of malnutrition among children under 5 years of age in Guiyang. China Maternal and Child Health. 2017;32,5400-5402.

[10]Man SL , Guo Y. Research on the social determinants of malnutrition among children under the age of 5 in China. Journal of Peking University. Health sciences, 2016,48(3):418-423.

[11]Yang Q, Zhang Y, Zhu GW, Xu X. Investigation and analysis of nutritional status of Tibetan children aged 0 to 7 in Saskan County, Tibet. Chinese Journal of Child Health. 2016;24,638-641.

[12]Yu DM, Liu AD, Yu WT, Zhang B, Zhang JG, Jia FM, et al. Malnutrition and its influencing factors in children under 5 years of age in poor areas of China in 2009. Health study. 2011;40,714-718.

[13]General Office of the State Council. Notice of the General Office of the State Council on Printing and Issuing National Nutrition Plan (2017-2030). http://www.gov.cn/zhengce/content/201707/13/content_5210134. Accessed 9 November 2019.

[14]Chen YZ, Tang XJ, Xu H, Wen J. Investigation on the status of growth and development of children under the age of 3 in the western minority area of sichuan and the analysis of the influencing factors. Journal of Shanghai Jiaotong University (Medical Edition). 2014;34,1805-1810.

[15]Jovana D, Chiara A, Mahamat B, Mark M, Brigitte P, Francois B, et al. Individual and household risk factors of severe acute malnutrition among under-five children in Mao, Chad: a matched case-control study. Archives of Public Health, 2018,76(1):35-.

[16]Wasihun AG, Dejene TA, Teferi M, Marugan J, Negash L, Yemane D, et al. Risk factors for diarrhoea and malnutrition among children under the age of 5 years in the Tigray Region of Northern Ethiopia. PLOS One. 2018,13(11):e0207743.

[17] Gizaw Z, Woldu W, Bitew BD. Acute malnutrition among children aged 6-59 months of the nomadic population in Hadaleala district, Afar region, northeast Ethiopia. Italian Journal of Pediatrics. 2018,44(1):21.

[18]World Health Organization. Child growth standards: The WHO Multicentre Growth Reference Study (MGRS). http://www.who.int/childgrowth/mgrs/en/. Accessed 9 November 2019. 
[19]Chen CM, Wu HE, Wang YY, Deng LN, Jia FM. Nutritional Status of Children during and post-Global Economic Crisis in China. Biomedical and environmental sciences: BES. 2011;24,321-8.

[20]Zhao SH, Lan ZY, Chen GH, Li X, Yao M. Investigation on growth, development and anemia of preschool children in minority areas of Guizhou Province. Journal of Guiyang Medical College. 2013,38,35-37.

[21]Chen R. Analysis of nutritional status and influencing factors of children under 6 years of age in four counties of Gansu province from 2006 to 2009. Master, Lanzhou University, Lanzhou, 2015.

[22]Du Plessis LM, Kruger HS, Sweet L. Complementary feeding: a critical window of opportunity from six months onwards. South African Journal of Clinical Nutrition. 2013;3,S129-S140.

[23]Wang J, Wang H, Chang S, Zhao L, Fu P, Yu W, et al. The Influence of Malnutrition and Micronutrient Status on Anemic Risk in Children under 3 Years old in Poor Areas in China. PLOS ONE. 2015;10.

[24]Zangmo U, de Onis M, Dorji T. The nutritional status of children in Bhutan: results from the 2008 National Nutrition Survey and trends over time. BMC Pediatrics. 2012;12,151.

[25]Li XQ, Zhang WS, Liu Y, Wu GF, Yan XF, Mao XM. Growth status of children under 7 years in Wuzhong City, Ningxia Hui Autonomous Region, China and its influential factors. Chinese Journal of Contemporary Pediatrics. 2013;15,289-293.

[26]Zhou WY, Wang XL, Luo SS, Wang Y. Study on stunting of children under 5 years of age in 50 counties of central and western China. Chinese Journal of Child Health. 2008;16,265-267.

[27]Wang Y, He YH, Zhang QJ, Wang QY, Feng XL. Analysis of influencing factors on growth retardation of children under 5 years of age in Jilin Province in 2013. Journal of the Chinese Academy of Medical Sciences. 2017,39(02):254.

[28]Capanzana MV, Aguila DV, Gironella GMP, Montecillo KV. Nutritional status of children ages 0-5 and 510 ? years old in households headed by fisherfolks in the Philippines. Archives of Public Health. 2018,76(1):24.

[29]Nagahori C, Tchuani JP, Yamauchi T. Factors associated with nutritional status in children aged 5-24 months in the Republic of Cameroon. Nursing \& Health Sciences. 2015;17,229-235.

[30]Kinyoki DK, Berkley JA, Moloney GM, Kandala NB, Noor AM. Predictors of the risk of malnutrition among children under the age of 5 years in Somalia. Public Health Nutrition. 2015;19,1-9.

[31]Neima E, Henok A, Lamessa D. Prevalence of Malnutrition and Associated Factors among Children in Rural Ethiopia. BioMed Research International. 2017;2017:1-6.

[32]Asim M, Nawaz Y. Child Malnutrition in Pakistan: Evidence from Literature. Children. 2018;5, 60-. 
[33]Ewusie JE, Beyene J, Ahiadeke C, Hamid JS. Malnutrition in Pre-school Children across Different Geographic Areas and Socio-Demographic Groups in Ghana. Maternal and Child Health Journal. 2017;21,797-808.

[34]Roy MP. Malnutrition in children and its determinants: a study from east India. Tropical Doctor. 2019;49,113-117.

[35]Horta BL, Santos RV, Welch JR, Cardoso AM, dos Santos JV, Assis AM, et al. Nutritional status of indigenous children: findings from the First National Survey of Indigenous People's Health and Nutrition in Brazil. International Journal Equity Health. 2013;12,23.

[36] Mekonnen A, Jones N, Tefera B. Tackling child malnutrition in Ethiopia: do the sustainable development poverty reduction programme's underlying policy assumptions reflect local realities? Working paper no 9. 2005, London: Young Lives, Save the Children UK.

[37]Kien VD, Lee HY, Nam YS, Oh J, Giang KB, Van Minh H. Trends in socioeconomic inequalities in child malnutrition in Vietnam: findings from the Multiple Indicator Cluster Surveys, 2000-2011. Global Health Action. 2016;9.

[38]Abdibari Ma'alin, Birhanu D, Melaku S, Tolossa D, Mohammed Y, Gebremicheal K. Magnitude and factors associated with malnutrition in children 6-59 months of age in Shinille Woreda, Ethiopian Somali regional state: a cross-sectional study. BMC Nutrition, 2016, 2(1).

[39]James P, Sadler K, Wondafrash M, Argaw A, Luo H, Geleta B, et al. Children with Moderate Acute Malnutrition with No Access to Supplementary Feeding Programmes Experience High Rates of Deterioration and No Improvement: Results from a Prospective Cohort Study in Rural Ethiopia. PLOS ONE. 2016,11(4):e0153530.

[40]Medhin G, Hanlon C, Dewey M, Alem A, Tesfaye F, Worku B, et al. Prevalence and predictors of undernutrition among infants aged six and twelve months in Butajira, Ethiopia: the P-MaMiE birth cohort. BMC Public Health. 2010;10(1):1.

[41] Schmidt MK, Muslimatun S, West CE, Schultink W, Gross R, Hautvast JG. Nutritional Status and Linear Growth of Indonesian Infants in West Java Are Determined More by Prenatal Environment than by Postnatal Factors. J Nutr. 2002,132 (8):2202-2207.

[42]Zhao YL, Tao Y. Research progress on the effects of water and sanitation on diarrhea. Journal of Environment and Health. 2008,25 (8):743-745.

[43]Jung YT, Hum RJ, Lou W, Cheng YL. Effects of neighbourhood and household sanitation conditions on diarrhea morbidity: Systematic review and meta-analysis. PLoS ONE. 2017,12(3):e0173808.

[44]Baker KK, O'Reilly CE, Levine MM, Kotloff KL, Nataro JP, Ayers TL, et al. Sanitation and HygieneSpecific Risk Factors for Moderate-to-Severe Diarrhea in Young Children in the Global Enteric Multicenter 
Study, 2007-2011: Case-Control Study. PLoS Med. 2016,13(5):e1002010. 